\title{
BULDAN DOKUMALARININ KULLANIM ALANININ ARTTIRILMASINA YÖNELIK BİR UYGULAMA ÇALIŞMASI
}

\author{
Emine UTKUN ${ }^{1}$, Melek ARPACI GÜNDOĞAN ${ }^{2}$
}

\section{ÖZET}

Ülkemizde Denizli ilinin Buldan ilçesi, kendisine has el dokuması kumaşlarından imal edilen, ev tekstili ve dış giyim mamulleri ile özdeşleşmiştir. Geçmişte burada kaftan, gömlek, gelinlik, üstlük, peştamal gibi ürünler üretilirken, günümüzde çağımızın giyim şekline uygun olarak fakat yine aynı özgünlük ve kalitede bluz, gömlek, elbise, şal, kravat, peştamal gibi ürünler üretilerek satışa sunulmaktadır.

$\mathrm{Bu}$ çalışmanın amacı, halen yörenin ticaretinde önemli bir yere sahip Buldan dokumalarının günümüzdeki kullanım alanını zenginleştirmeye yönelik yaratıcı çalışmalar sunmaktır.

Anahtar Kelimeler: Buldan dokumaları, giysi tasarımı, Buldan.

\section{AN APPLICATION STUDY AIMED AT IMPROVING THE USAGE AREA OF BULDAN WEAVING}

\section{ABSTRACT}

Buldan city of Denizli state in our country is identified with the home textiles and outerwear items which are manufactured from its unique hand woven fabrics. While the products such as caftan, shirt, wedding dress, robe and loincloth were manufactured here in the past, the products such as blouse, shirt, dress, scarf, tie and loincloth are manufactured and sold today in accordance with the age's clothing style but with the same originality and quality.

The aim of this study is to present creative works intended for enriching the current usage area of Buldan weaving, which still has a very important place in the trade of the region.

Keywords: Buldan weaving, clothing design, Buldan. 


\section{Giriş}

Anadolu'da, Denizli ve çevresi dokumacılığın sürekli geçim kaynağı olduğu merkezlerden bir tanesidir. Denizli dokumacılığının ana merkezlerinden birisinin de Buldan ilçesi olduğu bilinmektedir.

Buldan el dokumacılığının geleneksel özelliklerinden olan ev-atölye birlikteliği, Orta Çağ zanaat üretimini andırır biçimde günümüzde de varlığını sürdürmektedir. Dokuma tezgâhı, genellikle avlunun bir köşesine veya evle bitişik bir ek uzantıya yerleştirilmiştir. Ev-atölye-aile iç içeliğinin olduğu bu yapı son yıllarda değişmeye başlamıştır. El dokumacılığın nesilden nesile aktarılmasında ev-atölye-aile iç içeliğinin katkısı büyüktür (Buldan Kaymakamlığı Resmi Web Sayfası, 2013).

1955 te gelişen tekstil sanayi, küçük el sanatları şeklindeki dokumacılığa darbe vurunca, teknoloji karşısında dokumacılar kişisel kurtuluşu makineleşmede bulmuşlardır. Bu dönemden sonra, el tezgahlarında hızla azalma başlamış ve otomatik tezgah sayısı da giderek artmıştır (Atalayer, 1980).

2009 yılında yapılan bir envanter çalışmasına göre ilçede 45 adet el dokuma tezgahı, 127 adet yarı otomatik dokuma tezgahı ve 102 adet otomatik dokuma tezgahı çalışır durumda faaliyet göstermektedir (Ertuğrul ve Utkun, 2009).

Buldan bezi uzun süreli kullanımlarda bile özelliğini ve niteliğini kaybetmemesi, aynı zamanda kimyasal malzemeler içermemesi dolayısıyla sağlıklı ve doğaldır. Dokuma tekniğine göre Buldan bezi, temel dokuma örgülerinin en basit ve sağlamı olan, bez ayağı dokuma örgüsündedir. Genellikle çok bükümlü ipliklerin atkı olarak kullanıldığı Buldan bezinde, hem atkı hem de çözgü ipliklerinin çok bükümlü olduğu örneklerde vardır. Dokuma; karakteristik, buruşuk yapısını, sıcak, sabunlu suda yıkanmasından sonra kazanır. İpliklerin büküm oranına göre eni daralan dokumanın, buruşuk yapısı ile vücut arasında hava kaldığı ve kumaş vücuda yapışmadığı için ısı yalıtımı sağlanır. Bu nedenle Buldan bezi genellikle iç giyimde kullanılmıştır (Uğurlu ve Uğurlu 2006).

Aynı zamanda Buldan bezi yüksek bükümlü iplikle dokunduğu için esnektir, vücudu sarar, yapısındaki kıvrımlar arasında hava boşlukları giysinin serin tutmasını sağlar ve sağlığa uygundur. Buldan bezi, yapısından dolayı "Buldan bükülüsü" adını almaktadır.

Bu çalışma kapsamında, halen yörenin ticaretinde önemli bir yere sahip Buldan dokumalarının günümüzdeki kullanım alanını zenginleştirmeye yönelik yaratıcı çalışmalar sunulmaktadır.

\section{Buldan Dokumalarından Üretilen Tasarımlar}

Bu bölümde Buldan dokumaları kullanılarak tasarlanan ve üretimleri gerçekleştirilen yedi adet modele ait resimler, teknik çizimler ve analizler verilmektedir.

Birinci tasarım omzunda altın renginden payetlere sahiptir. Belindeki geometrik şekillerden oluşan kemeri arkaya doğru uzanmaktadır. Bele kadar oturan bu modelin etek kısmı bol volanlarla, vücudu sarmaktadır. Yakası V yakalı bir modeldir (Şekil 1).

Arka da ise V yaka gelen model, zincirlerle karşılıklı tutturulmuştur. Öndeki kemerin ipi, arkada fiyonk şeklinde bağlanmıştır. Öndeki volanlı etek kıvrımları arkada da devam etmiştir.

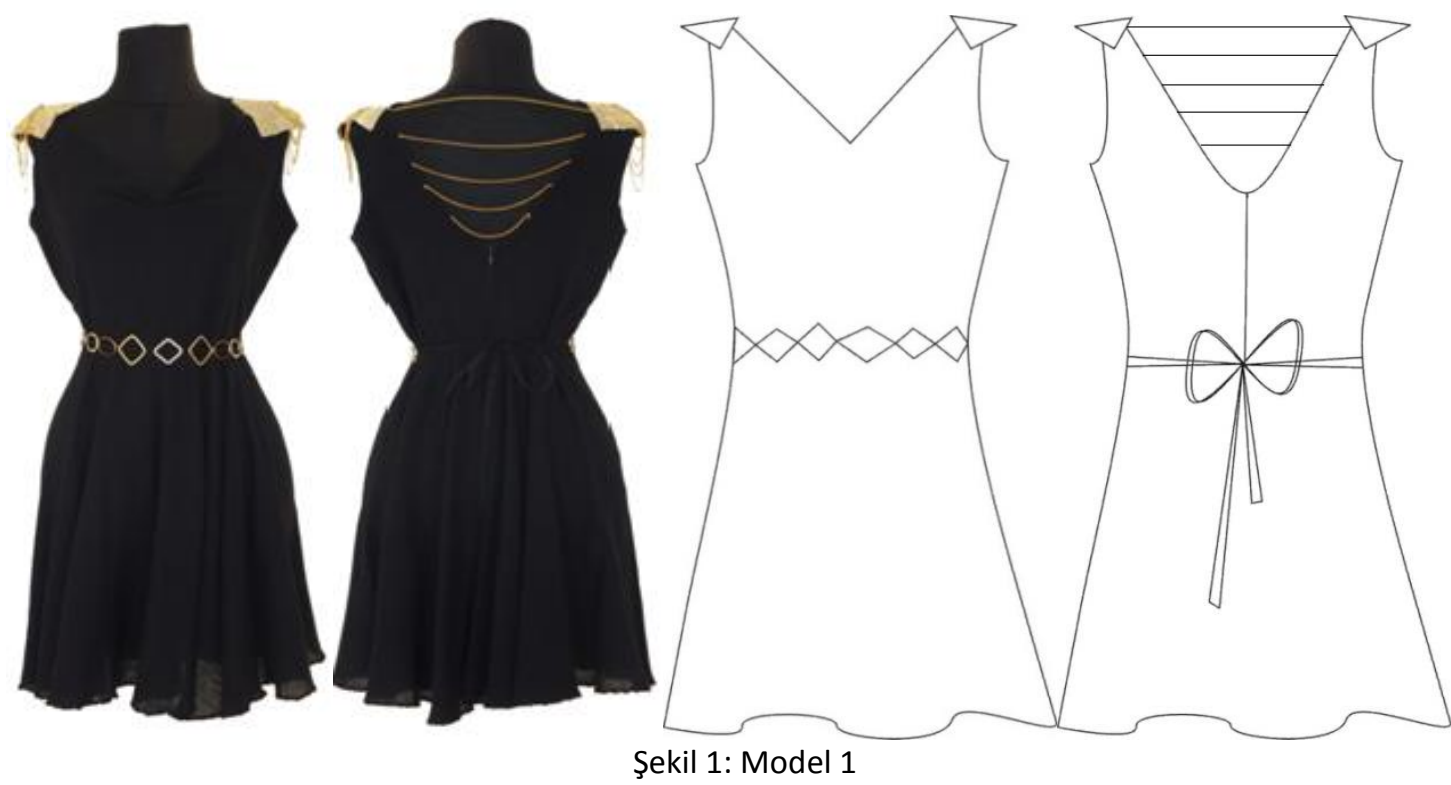


İkinci tasarımda düz straplez elbise üzerini atılan bolero, çeşitli nakışlardan oluşmaktadır. Bolero V yakalıdır. Kolsuz olan boleronun özelliği, omuzdan dar başlayarak bele doğru açılan kumaşıdır. Simetrik bir tasarımdır. Arkada ise simetrik nakışlar yer almaktadır. Elbise düz kesimiyle dizlere kadar uzanmaktadır (Şekil 2).
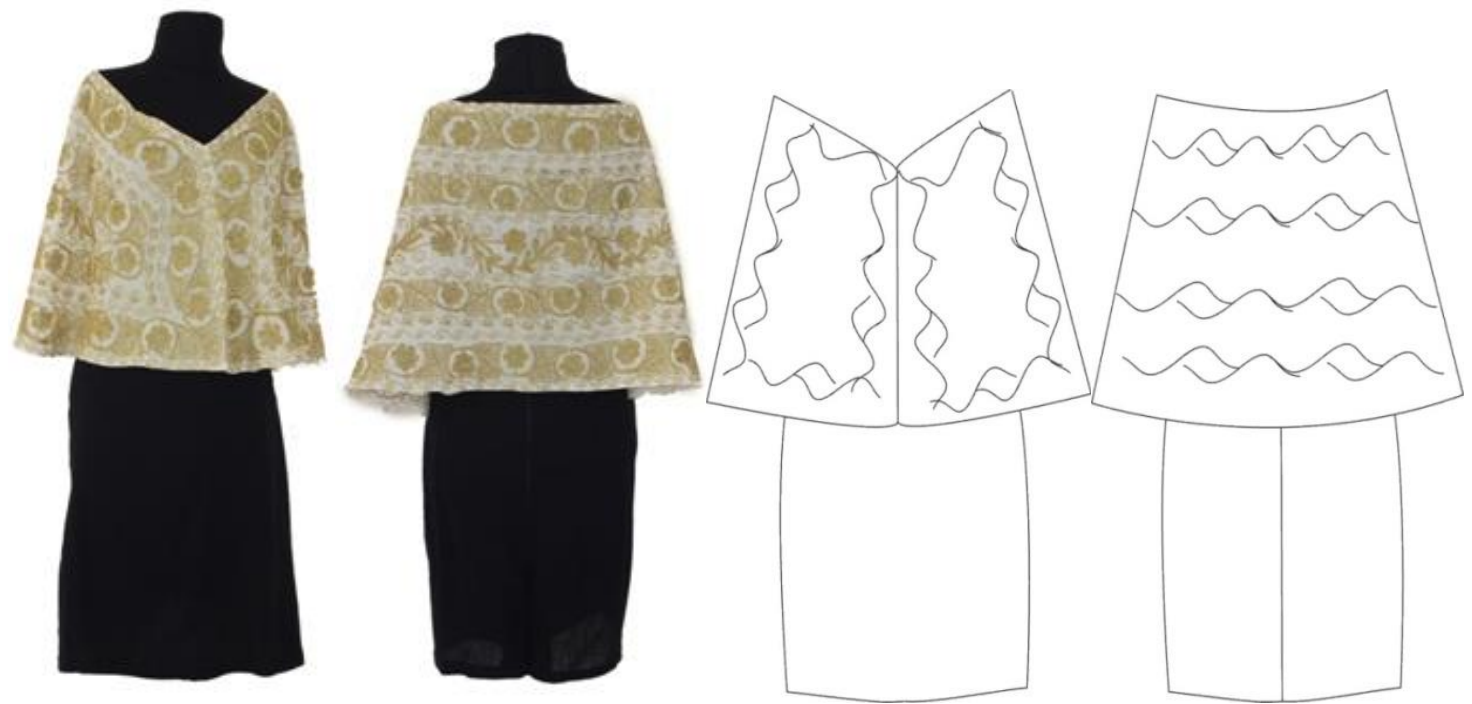

Şekil 2: Model 2

Üçüncü tasarımda sadelik ön planda olup, pul işlemesiyle süslemesi yapılmıştır. Önde ilk göze çarpan işleme detayı olurken, arkada ilk göze çarpan ise kemerin fiyonk şeklindeki halidir (Şekil 3).

Simetrik bir modeldir. Diğer tasarımlarda olduğu gibi bu tasarım da tamamen Buldan bezinden üretilmiştir. Etek ucunda hazır dantel şeritlerden yararlanılmaktadır. Kolsuz olan bu modelin, sırt dekoltesi dikkat çekmektedir. ' $V$ ' şeklinde olan sırt dekoltesi, etek ucunda kullanılan dantel şeritlerle oluşturulmuştur. Elbise boyu ise dizlere kadar uzanmaktadır.
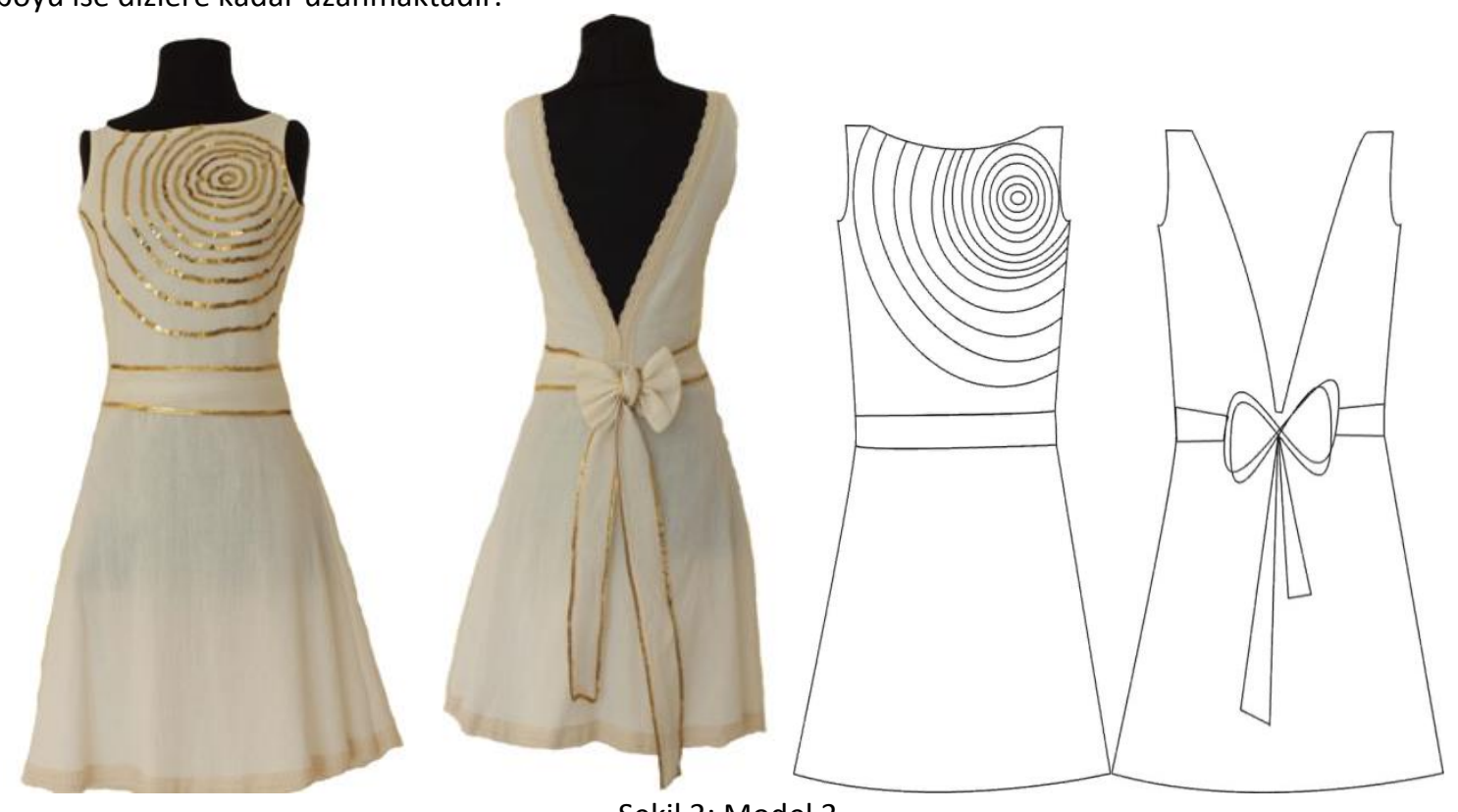

Şekil 3: Model 3

Dördüncü tasarım asimetrik ve askılı bir modeldir. Etek ucu kalçanın aşağısından başlayıp, dizin hizasına kadar uzanmaktadır. Kalp şeklindeki yakası, şeritlerle süslenmektedir. Belindeki kemer yanda fiyonk yapılarak birleşmektedir. Arka üst bedeni ise yine asimetrik olup, şeritlerle süslenmiştir (Şekil 4). 

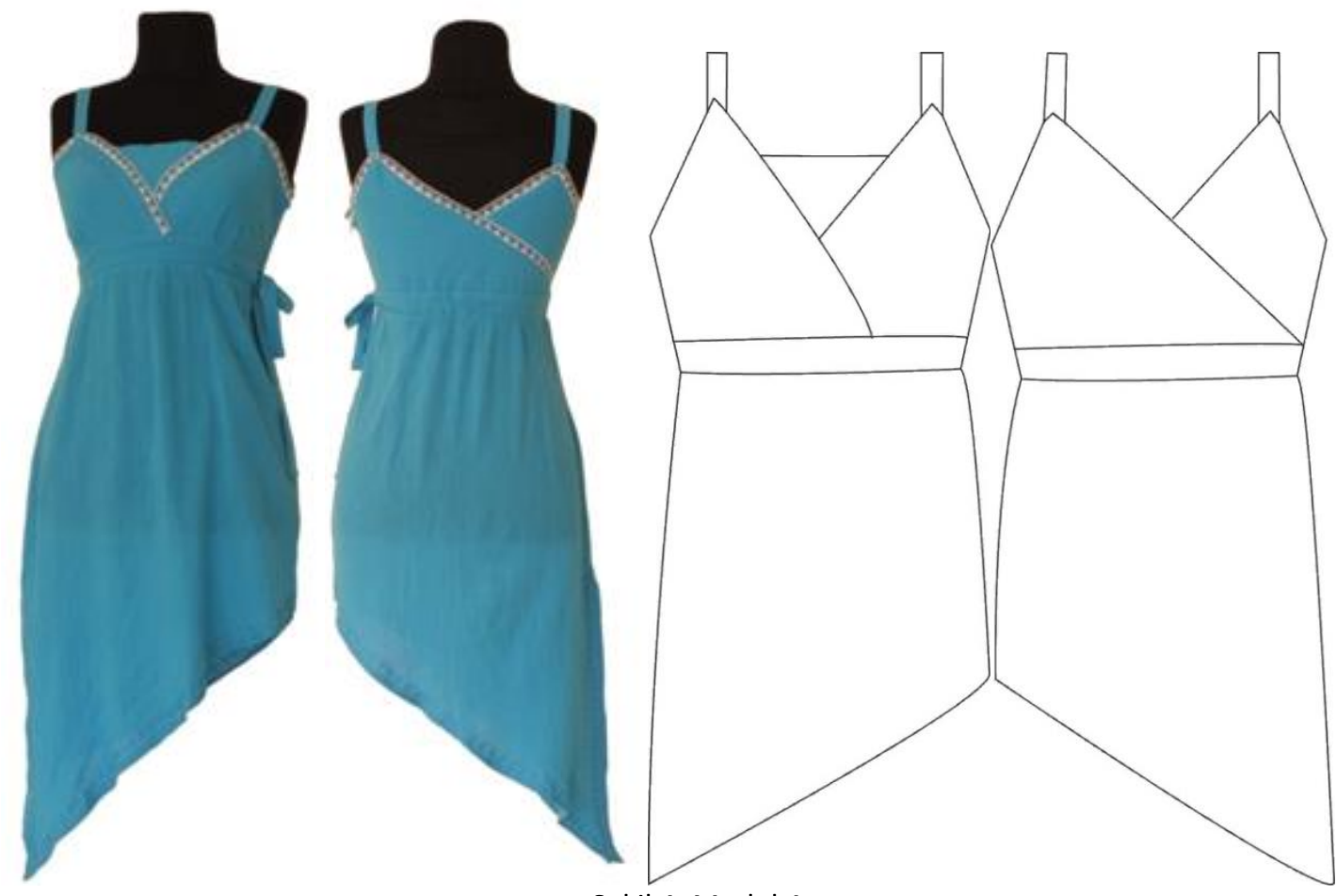

Şekil 4: Model 4

Beşinci tasarım iki zıt rengin aynı anda kullanılmasıyla oluşmaktadır. Bu renkler ön ortasından birbirinden ayrılmaktadır. Model ön ve arkada aynı görünüşe sahiptir. Etek ucu asimetrik olup, çapraz şekilde birleşmektedir. Bel oyuntusunu sağlamak amaçlı bele kemer tasarlanmıştır. 'V' yaka olup, yaka kenarlarına şerit süsleme yapılmıştır (Şekil 5).
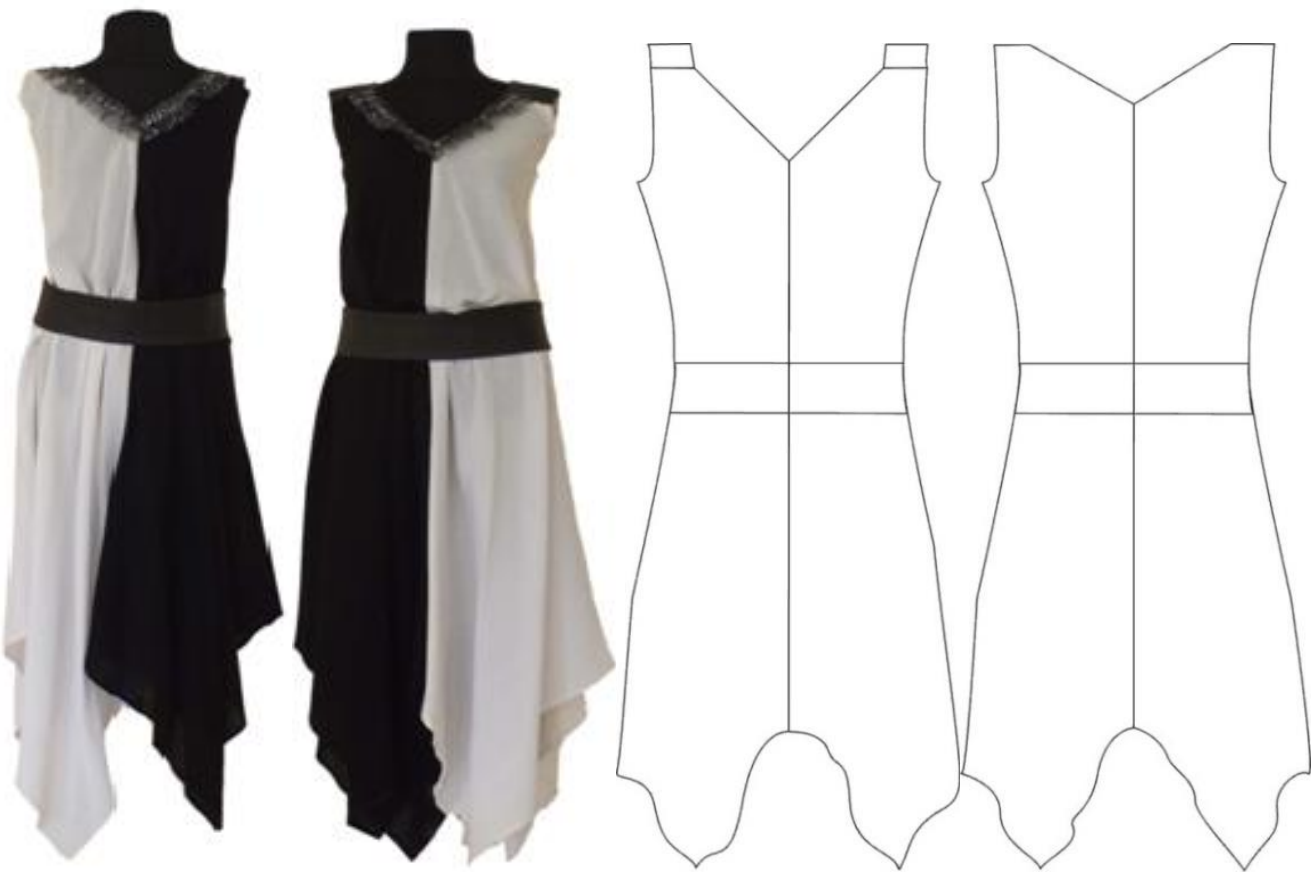

Şekil 5: Model 5

Altıncı tasarım asimetrik bir modeldir. Yakası bisiklet yakadır. Kollu olan bu modelin, orta kısmı dalgalı tasarlanmıştır. Bu da giysiye hareket kazandırmaktadır. Süsleme amaçlı hazır çiçekler kullanılmaktadır. Yan dikişin hizasına fermuar eklenmiştir. Arka kısmı ise daha sade ve düzdür (Şekil 6). 

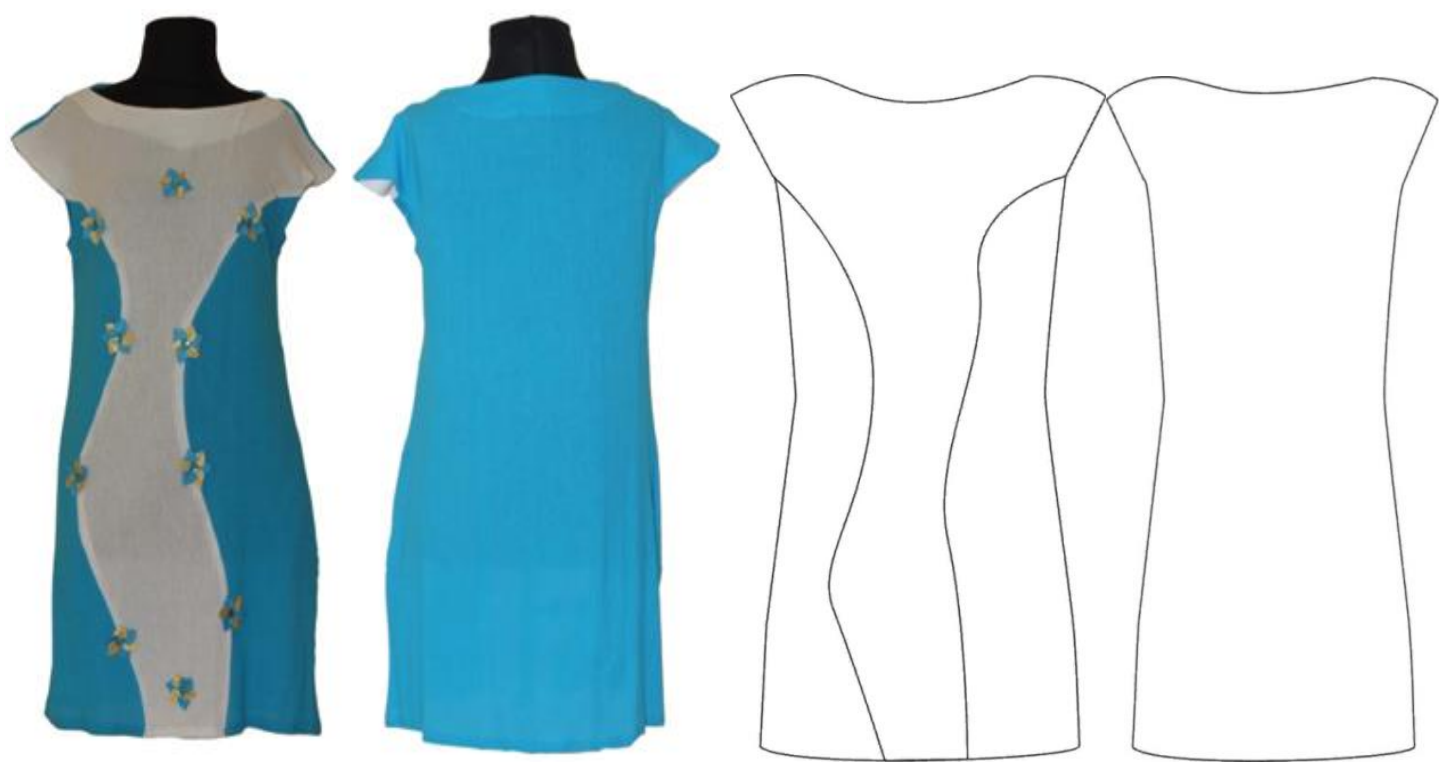

Şekil 6: Model 6

Yedinci tasarımın modeli tulum şeklindedir. 'V' yaka olarak tasarlanmıştır. Sağ yandaki nakış işlemesi, süsleme amaçlı kullanılmaktadır. Beldeki kemer papatyalı bir desenden oluşturulmuştur. Tasarımda bolluk ön plandadır. Paça boyu ayak bileğine kadar uzamaktadır (Şekil 7).
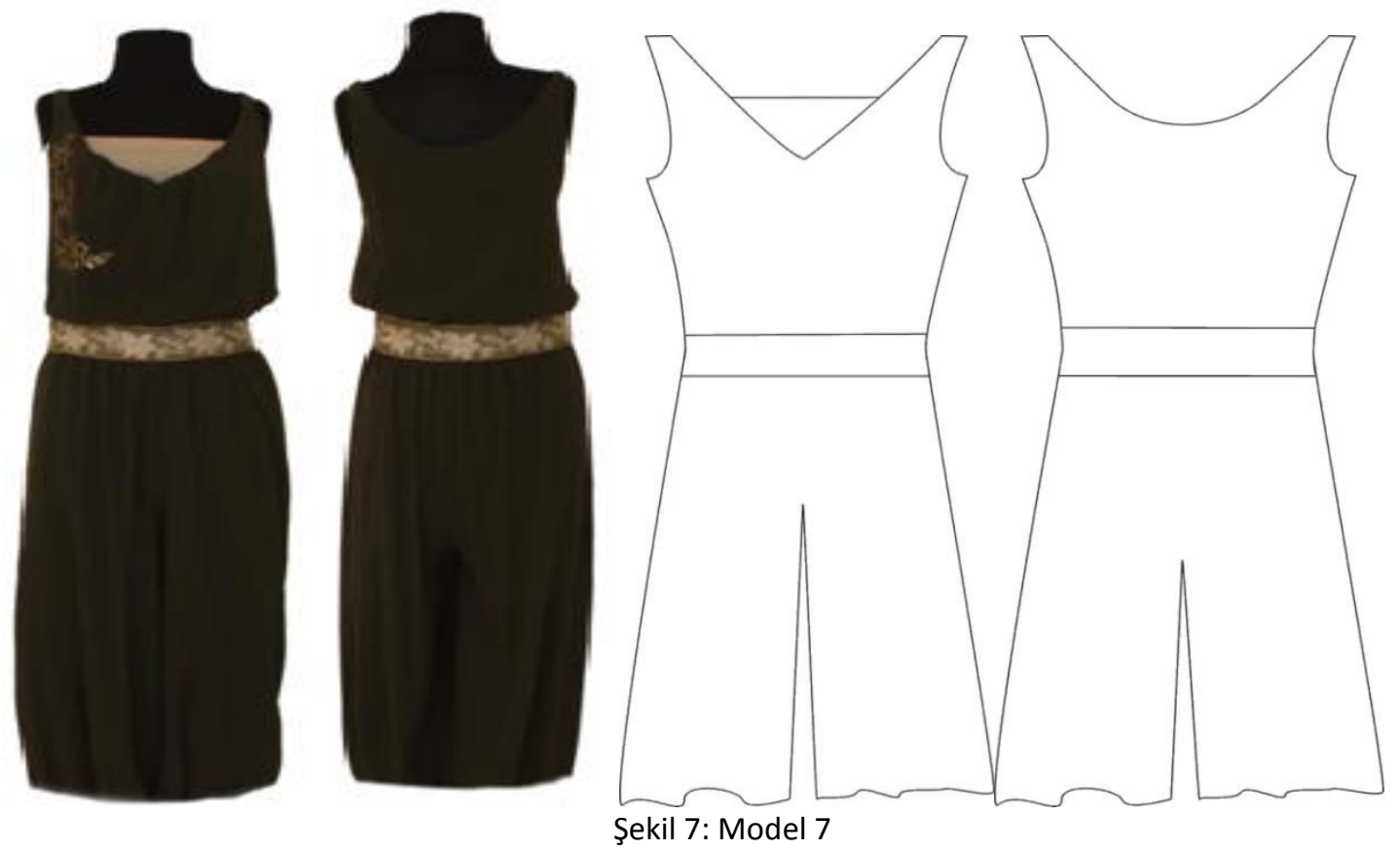

\section{Sonuç}

Buldan dokumalarının kullanım alanlarının arttırılarak ekonomiye kazandırılması ile ilgili çalışmalar ülkemiz ekonomisi açısından büyük öneme sahiptir. Bu tarz yöresel kumaşların, mevcut tasarımlardan farklı tasarımlara ve yeni yorumlara ihtiyacı vardır. Bu çalışma kapsamında yedi adet modern giysi tasarlanmış ve üretilmiştir. Üretilen giysilerin ise gerek Buldan'da gerekse Denizli'de düzenlenen farklı defileler aracılığıyla tanıtımı sağlanmıştır.

\section{Kaynakça}

Buldan Kaymakamlığı (2014). Resmi Web Sayfası: www.buldan.gov.tr, Erişim: Ağustos 2014.

Ertuğrul, i., Utkun, E. (2009). Buldan Tekstil Sanayiinin Gelişimi ve Envanter Araştırması. Bursa: Ekin Yayınları. 
Atalayer, G. (1980). Buldan Dokumaları. İstanbul: Devlet Tatbiki Güzel Sanatlar Yüksekokulu, Yayınlanmamış Sanatta Yeterlik Tezi.

Uğurlu, A., Uğurlu, S.S. (2006). Yörenin Kültürel Kimliği Olarak Buldan Bezi. Buldan Sempozyumuna Sunulmuş Bildiri, Denizli. 